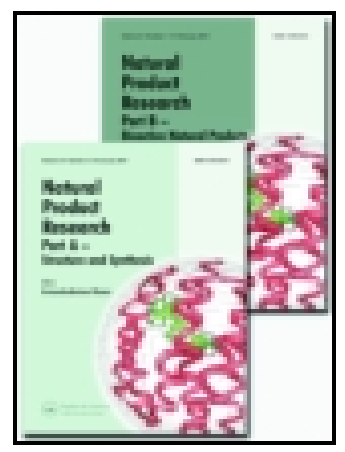

Natural Product Research

Formerly Natural Product Letters

ISSN: 1478-6419 (Print) 1478-6427 (Online) Journal homepage: http://www.tandfonline.com/loi/gnpl20

\title{
Madeira moneywort (Sibthorpia peregrina L.) as a new source of verbascoside and its derivatives with potential phyto-pharmaceutical applications
}

\author{
Vítor Spínola \& Paula C. Castilho
}

To cite this article: Vítor Spínola \& Paula C. Castilho (2018): Madeira moneywort (Sibthorpia peregrina L.) as a new source of verbascoside and its derivatives with potential phytopharmaceutical applications, Natural Product Research, DOI: 10.1080/14786419.2018.1474354

To link to this article: https://doi.org/10.1080/14786419.2018.1474354

View supplementary material ¿

Published online: 25 May 2018.

Submit your article to this journal $₫$

View related articles $\circlearrowright$

View Crossmark data $\nearrow$ 


\title{
Madeira moneywort (Sibthorpia peregrina L.) as a new source of verbascoside and its derivatives with potential phyto-pharmaceutical applications
}

\author{
Vítor Spínola (iD and Paula C. Castilho \\ CQM - Centro de Química da Madeira, Universidade da Madeira, Campus da Penteada, Funchal, Portugal
}

\begin{abstract}
The qualitative and quantitative characterization of Madeira moneywort (Sibthorpia peregrina L.) compounds was investigated for the first time. The antioxidant activity and the effect of the methanolic extract on digestive enzymes activity linked to type-2 diabetes and obesity were also determined by in vitro assays. A total of 56 components were characterized in S. peregrina. Phenylethanoids glycosides (PhEGs) represented the main classes of compounds (95.23 $\mathrm{mg} \mathrm{g}^{-1}$ of dry extract), almost all verbascoside and its derivatives (up to $98.85 \%$ of the total individual phenolic content). The analysed sample was active against ABTS, DPPH, nitric oxide and superoxide radicals, suggesting a potential beneficial effect against oxidative stress. In addition, the methanolic extract was able to inhibit the catalytic activity of $\alpha-, \beta$-glucosidases, $\alpha$-amylase and pancreatic lipase. Overall, S. peregrina showed good perspectives to be explored as a rich source of verbascoside and its derivatives for nutraceutical/ pharmaceutical products.
\end{abstract}
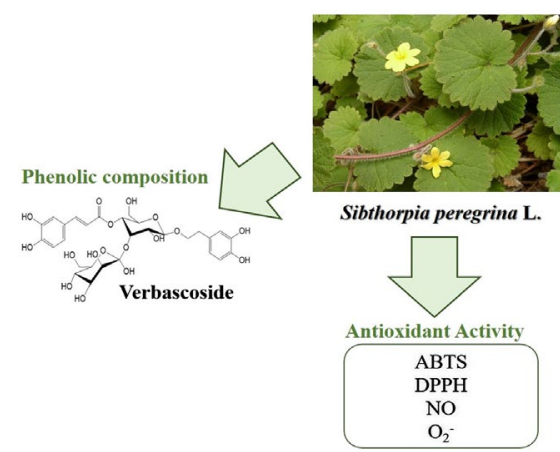

ARTICLE HISTORY

Received 12 December 2017 Accepted 3 May 2018

\section{KEYWORDS}

Sibthorbia peregrina L.; Madeira moneywort; phenolic composition; verbascoside; antioxidant activity; digestive enzymes inhibition

\section{CONTACT Paula C. Castilho castilho@uma.pt}

(1) Supplemental data for this article can be accessed at https://doi.org/10.1080/14786419.2018.1474354. 


\section{Introduction}

Verbascoside (also known as acteoside or kusagin) (Figure S1) has been shown to possess extensive beneficial effects on human health, namely antioxidant, anti-inflammatory and antimicrobial in addition to wound-healing, photo-, hepato- and neuroprotective properties (He et al. 2011; Alipieva et al. 2014). Due to its low side effects and toxicity, this molecule is very promising for development of phyto-pharmaceuticals (Funes et al. 2009; He et al. 2011).

Madeira moneywort (Sibthorpia peregrina L.; Plantaginaceae) locally known as 'erva terrestre' or 'erva redonda' it is a low creeping perennial herb endemic to Madeira archipelago (Portugal). Hot infusions and decoction of its leaves were used in folk medicine for relieving cough and as an expectorant (Rivera and Obón 1995). Despite its medicinal use, its phytochemical composition remains unknown. Verbascoside has been reported as the main compound in the Sibthorpia genera (Taskova et al. 2006). Therefore, the main goal of this work was to determine the polyphenolic profile of S. peregrina leaves. Additionally, the in vitro antioxidant and digestive enzymes inhibitory activities of methanolic extract were assessed.

\section{Results and discussion}

\subsection{Phytochemical characterization}

Among the 56 compounds identified by HPLC-ESI-/MSn, there were 34 phenylethanoid glycosides (PheGs) (in particular verbascoside derivatives), 10 phenolic acids, 3 flavonoids and 8 other phytochemicals (lignans, fatty acids, and saccharides) (Table S1 and Figure S2).

\subsection{Quantification of main polyphenols}

Results showed that PhEGs were the dominant phenolic group (99.19\% of TIPC) of S. peregrina, adding up to $96 \mathrm{mg} . \mathrm{g}^{-1} \mathrm{DE}$, mainly verbascoside I (84.89\% of TIPC) (Table 1 and Supplementary Material). By comparison, Penstemon barbatus and Plantago spp. (Plantaginaceae) and S. europaea showed lower verbascoside contents (6 - $27.49 \mathrm{mg} \mathrm{g}^{-1} \mathrm{DE}$ ) (Taskova et al. 2006; Xie et al. 2012; Gonçalves et al. 2015). S. africana had superior amounts of verbascoside (540 $\mathrm{mg} \mathrm{g}^{-1} \mathrm{DE}$ ) (Taskova et al. 2006), but it only corresponded to $18 \%$ of polyphenolic contents. So, S. peregrina emerges as an interesting alternative source for extraction of verbascoside and its derivatives, since the high percentage of these compounds $(\approx 99 \%$ of TIPC) in the analysed extract facilitates the process of isolation and purification from the mixture.

\subsection{In vitro antioxidant activities}

S. peregrina extract showed interesting antiradical activities (Table 2). In fact, it was more effective than two well-known verbascoside-rich plants, Plantago spp. (0.27 - $0.78 \mathrm{mmol}$ TE $\mathrm{g}^{-1} \mathrm{DE}$ ) (Gonçalves et al. 2015) and Lippia citrodora (1.15 mmol TE g ${ }^{-1} \mathrm{DE}$ ) (Funes et al. 2009) towards ABTS and DPPH radicals, respectively. This could be due to their lower verbascoside contents which, in both cases is a small percentage of complex mixtures (Supplementary Material). The inhibition of $\mathrm{NO}$ and $\mathrm{O}_{2}^{-}$(Table 2 ) is more biologically relevant than that of non-biological radicals, being indicative of the potential of $S$. peregrina to prevent oxidative damage (Harput et al. 2012). The obtained results (Table 2) are assumedly due to the high 
Table 1. Quantification ( $\mathrm{mg} \mathrm{g}^{-1}$ of dry extract) of main polyphenols present in S. peregrina methanolic extract by HPLC-DAD.

\begin{tabular}{llll}
\hline No. & {$[\mathrm{M}-\mathrm{H}]^{-}$} & Assigned identification & Content \\
\hline Hydroxycinnamic acids & & & \\
2 & 353 & Caffeoylisocitrate & $0.15 \pm 0.01$ \\
7 & 487 & Caffeic acid-O-rutinoside & $0.27 \pm 0.01$ \\
8 & 493 & Coumaric acid derivative & $0.08 \pm 0.01$ \\
9 & 353 & 4-O-Caffeoylquinic acid & $0.05 \pm 0.01$ \\
Total & & & $0.55 \pm 0.01$ \\
Flavones & & & \\
17 & 593 & Vicenin-2 & $0.22 \pm 0.01$ \\
Total & & & $0.22 \pm 0.01$ \\
Phenylethanoids & & & \\
6 & 643 & Verbascoside derivative & $0.07 \pm 0.01$ \\
15 & 641 & Verbascoside derivative & $0.08 \pm 0.01$ \\
20 & 639 & B-Hydroxyverbascoside & $0.88 \pm 0.01$ \\
21 & 639 & B-Hydroxyverbascoside & $0.80 \pm 0.03$ \\
23 & 785 & Echinacoside II & $0.16 \pm 0.01$ \\
28 & 653 & Campneoside & $0.32 \pm 0.01$ \\
29 & 769 & Poliumoside I & $7.81 \pm 0.07$ \\
30 & 623 & Verbascoside I & $81.50 \pm 0.70$ \\
37 & 623 & Verbascoside IV & $1.98 \pm 0.04$ \\
38 & 753 & Forsythoside B I & $0.42 \pm 0.01$ \\
44 & 637 & Eukovoside I & $0.35 \pm 0.01$ \\
50 & 667 & Verbascoside derivative & $0.06 \pm 0.01$ \\
55 & 623 & Verbascoside VI & $0.50 \pm 0.01$ \\
56 & 623 & Verbascoside VII & $0.29 \pm 0.01$ \\
Total & & & $95.23 \pm 0.89$ \\
TIPC & & $96.01 \pm 0.67$ \\
\hline
\end{tabular}

Notes: Data represent the mean \pm standard deviation $(n=3)$. Bold values represent the sum of each type of components.

Table 2. In vitro antioxidant and digestive enzymes inhibitory activities of S. peregrina.

\begin{tabular}{lcccc}
\hline Antioxidant activity $^{*}$ & ABTS $^{+}$ & DPPH & NO & $\mathrm{O}_{2}$ \\
\hline S. peregrina & $3.74 \pm 0.13$ & $0.93 \pm 0.03$ & $0.49 \pm 0.02$ & $0.40 \pm 0.01$ \\
Enzyme inhibition $^{* *}$ & $\alpha$-Glucosidase & $\beta$-glucosidase & a-Amylase & Lipase \\
S. peregrina & $1.56 \pm 0.06^{\mathrm{c}}$ & $1.15 \pm 0.05^{\mathrm{b}}$ & $4.79 \pm 0.14^{\mathrm{b}}$ & $2.31 \pm 0.13^{\mathrm{b}}$ \\
Acarbose & $0.12 \pm 0.01^{\mathrm{b}}$ & - & $0.02 \pm 0.01^{\mathrm{a}}$ & - \\
1-Deoxynojirimycin & $0.01 \pm 0.01^{\mathrm{a}}$ & $0.45 \pm 0.02^{\mathrm{a}}$ & - & - \\
Conduritol B epoxide & - & $8.94 \pm 0.19^{\mathrm{c}}$ & - & - \\
Orlistat & - & - & - & $0.47 \pm 0.02^{\mathrm{a}}$
\end{tabular}

Notes: Data represent the mean \pm standard deviation $(n=3)$.

Means in the same column not sharing the same letter are significantly different at $p<0.05$ probability level.

${ }^{*}$ Results expressed as mmol TE ${ }^{-1}$ of dry extract.

"Results expressed as the $\mathrm{IC}_{50}$ value $\left(\mathrm{mg} \mathrm{mL}^{-1}\right)$.

content of verbascoside and its derivatives. Previous works (Funes et al. 2009; Harput et al. 2012; Timóteo et al. 2015; Mihailovic et al. 2016) had similar observations. Several in vitro and in vivo studies have demonstrated the powerful antioxidant effects of verbascoside by scavenging of biological free radicals, metal chelation activities, cellular protection against oxidizing agents, inhibition of lipid peroxidation and hemolysis of erythrocytes, and enhancement of endogenous antioxidant defenses (Funes et al. 2009; He et al. 2011; Cardinali et al. 2012; Alipieva et al. 2014; Gonçalves et al. 2015; Mihailovic et al. 2016). The four hydroxyls at the ortho position (catechol groups) in the two aromatic rings of verbascoside are the main responsible for its remarkable antioxidant activities (Alipieva et al. 2014). 


\subsection{In vitro digestive enzymes inhibition assays}

Inhibition of intestinal digestive enzymes, linked to sugar and fat metabolism, is recognized as an efficient therapeutic strategy to prevent diabetic complications and weight gain (Liu et al. 2014; Wu et al. 2014). Previously (Liu et al. 2014; Wu et al. 2014, 2017), verbascoside and other PhEGs were described as effective inhibitory agents of $\alpha$-glucosidase and pancreatic lipase (PL). Therefore, the inhibitory potential of S. peregrina against key digestive enzymes linked to type-2 diabetes and obesity was evaluated. S. peregrina effectively inhibited targeted enzymes (Table 2), although positive controls displayed higher activities $(p<0.05)$. Caffeic and chlorogenic acids are strong glucosidases inhibitors (Xiao et al. 2013). Considering the verbascoside structure (Figure S1), it can be inferred that the presence of a caffeic acid moiety has a key role in the obtained results (Table 2). Structure-activity studies showed also that the presence of two catechol groups in verbascoside (Figure S1) is determinant for its strong binding affinities and inhibition for PL (Wu et al. 2014, 2017). In fact, increasing the number of phenolic groups in PhEGs remarkably improves the binding with PL (Wu et al. 2017). The hydrogen bonding interactions (non-covalent) between the catechol groups of verbascoside and the polar groups of PL are important for protein conformational change, thus affecting the enzyme catalytic activity (Wu et al. 2014, 2017).These results demonstrate the potential hypoglycemic and hypolipiademic effects of verbascoside-rich plant extracts and their application in the prevention/control of type II diabetes and obesity.

\section{Experimental}

The methodologies used in this work are described in detail in Supplementary Material.

\section{Conclusions}

The present work demonstrated that verbascoside and its derivatives are the most abundant compounds of S. peregrina extract. Based on the displayed in vitro antiradical scavenging properties, S. peregrina might potentially prevent chronic pathologies associated with oxidative stress. In addition, the methanolic extract exhibited moderate inhibitory effects against digestive enzymes linked to sugars and fats metabolism. These results provide a valuable foundation for further research on this species as potential novel source of easily purifiable verbascoside with pharmacologic perspectives. Nevertheless, the effects of S. peregrina in cell-based models and animal experiments need further research in order to validate its potential bioactivities.

\section{Disclosure statement}

No potential conflict of interest was reported by the authors. 


\section{Funding}

This work was supported by Fundação para a Ciência e a Tecnologia (FCT, Portugal) [grant number SFRH/ BD/84672/2012] with funds from the Portuguese Government (Project PEst-OE/QUI/UI0674/2013) and the Portuguese National Mass Spectrometry Network (Contract RNEMREDE/1508/REM/2005). Funding through the project M1420-01-0145-FEDER-000005 - Centro de Química da Madeira - CQM+(Madeira 14-20).

\section{ORCID}

Vítor Spínola (D) http://orcid.org/0000-0003-2456-8613

\section{References}

Alipieva K, Korkina L, Orhan IE, Georgiev MI. 2014. Verbascoside - A review of its occurrence, (bio) synthesis and pharmacological significance. Biotechnol Adv. 32:1065-1076.

Cardinali A, Pati S, Minervini F, D'Antuono I, Linsalata V, Lattanzio V. 2012. Verbascoside, Isoverbascoside, and their derivatives recovered from Olive Mill wastewater as possible food antioxidants. J Agric Food Chem. 60:1822-1829.

Funes L, Fernández-Arroyo S, Laporta O, Pons A, Roche E, Segura-Carretero A, Fernández-Gutiérrez A, Micol V. 2009. Correlation between plasma antioxidant capacity and verbascoside levels in rats after oral administration of lemon verbena extract. Food Chem. 117:589-598.

Gonçalves S, Grevenstuk T, Martins N, Romano A. 2015. Antioxidant activity and verbascoside content in extracts from two uninvestigated endemic Plantago spp. Ind Crops Prod. 65:198-202.

Harput US, Genc Y, Saracoglu I. 2012. Cytotoxic and antioxidative activities of Plantago lagopus L. and characterization of its bioactive compounds. Food Chem Toxicol. 50:1554-1559.

He J, Hu XP, Zeng Y, Li Y, Wu HQ, Qiu RZ, Ma WJ, Li T, Li CY, He ZD. 2011. Advanced research on acteoside for chemistry and bioactivities. J Asian Nat Prod Res. 13:449-464.

Liu Q, Hu HJ, Li PF, Yang YB, Wu LH, Chou GX, Wang ZT. 2014. Diterpenoids and phenylethanoid glycosides from the roots of Clerodendrum bungei and their inhibitory effects against angiotensin converting enzyme and a-glucosidase. Phytochemistry. 103:196-202.

Mihailovic V, Kreft S, Benkovic ET, Ivanovic N, Stankovic MS. 2016. Chemical profile, antioxidant activity and stability in stimulated gastrointestinal tract model system of three Verbascum species. Ind Crop Prod. 89:141-151.

Rivera D, Obón C. 1995. The ethnopharmacology of Madeira and Porto Santo Islands, a review. J Ethnopharmacol. 46:73-93.

Taskova RM, Gotfredsen CH, Jensen SR. 2006. Chemotaxonomy of Veroniceae and its allies in the Plantaginaceae. Phytochemistry. 67:286-301.

Timóteo P, Karioti A, Leitão SG, Vincieri FF, Bilia AR. 2015. A validated HPLC method for the analysis of herbal teas from three chemotypes of Brazilian Lippia alba. Food Chem. 175:366-373.

Wu X, He W, Zhang H, Li Y, Liu Z, He Z. 2014. Acteoside: a lipase inhibitor from the Chinese tea Ligustrum purpurascens kudingcha. Food Chem. 142:306-310.

Wu X, Feng Y, Lu Y, Li Y, Fan L, Liu L, Wu K, Wang X, Zhang B, He Z. 2017. Effect of phenolic hydroxyl groups on inhibitory activities of phenylpropanoid glycosides against lipase. J Funct Foods. 38:510-518.

Xiao J, Kai G, Yamamoto K, Chen X. 2013. Advance in dietary polyphenols as a-glucosidases inhibitors: a review on structure-activity relationship aspect. Crit Rev Food Sci Nutr. 53:818-836.

Xie J, Tan F, Zhu J, Yue C, Li Q. 2012. Separation, purification and quantification of verbascoside from Penstemon barbatus (Cav.) Roth. Food Chem. 135:2536-2541. 